\title{
ESTIMASI SUMBERDAYA BATUBARA SEAM 1 MENGGUNAKAN METODE CIRCULAR 891 USGS DAERAH TANAH MERAH, KOTA SAMARINDA PROVINSI KALIMANTAN TIMUR
}

\author{
Muhammad Dahlan Balfas*, Retno Anjarwati, Koeshadi Sasmito, Muhammad Zaenal \\ Muhtadin, Yuyun Giska Oviandari
}

Teknik Geologi, Universitas Mulawarman, Jl. Sambaliung No.9 Samarinda 75119, Indonesia

*Corresponding author. Email: mdbalfas@yahoo.com

Manuscript received: 4 March 2021; Received in revised form: 27 April 2021; Accepted: 30 April 2021

\begin{abstract}
Abstrak
Tujuan dari penelitian ini adalah untuk mengetahui tonase batubara berdasarkan tingkat kepercayaan geologi ke dalam kategori sumberdaya tereka, tertunjuk, dan terukur menggunakan metode Circular 891 USGS. Penelitian ini juga dilakukan melalui pemetaan geologi detail daerah penelitian yaitu di Desa Tanah Merah, Kota Samarinda, kemudian dilakukan korelasi antar singkapan batubara guna mengetahui sebaran batubara tersebut. Setelah mengetahui sebaran batubara dapat dilakukan perhitungan sumberdaya tereka, tertunjuk dan terukur. Data yang diperoleh dari penelitian ini yaitu data singkapan batubara yang ditemukan di daerah penelitian. Data hasil pengamatan lapangan yang telah didapatkan kemudian diolah menggunakan rumus perhitungan volume dan tonase batubara, untuk sumberdaya tereka diperoleh hasil $945.468,74 \mathrm{~m}^{3}$, tertunjuk diperoleh hasil 700.020,23 $\mathrm{m}^{3}$, sedangkan untuk sumberdaya terukur diperoleh hasil $349.335,77 \mathrm{~m}^{3}$, kemudian dikalikan dengan densitas batubara yaitu $1,3 \mathrm{ton} / \mathrm{m}^{3}$. Estimasi sumberdaya tereka dengan radius $750 \mathrm{~m}$ diperoleh tonase sebesar 1.229.109,36 ton, sumberdaya tertunjuk dengan radius $500 \mathrm{~m}$ diperoleh tonase sebesar 910.026,30 ton. Sedangkan sumberdaya terukur dengan radius $250 \mathrm{~m}$ diperoleh tonase sebesar 454.136,50 ton.
\end{abstract}

Kata Kunci: batubara; estimasi; metode Circular 891 USGS; sumberdaya.

\begin{abstract}
The purpose of this study was to determine the tonnage of coal based on the level of geological confidence in the inferred, indicated, and measured resource categories using the Circular 891 USGS method. This research was also carried out through detailed geological mapping of the research area, it is in Tanah Merah, City of Samarinda, then the correlation between coal outcrops was carried out to determine the distribution of the coal. After knowing the distribution of coal, it is possible to calculate inferred, indicated and measured resources. The data obtained from this study are coal outcrop data found in the study area. The data from field observations that have been obtained are then processed using the formula for calculating the volume and tonnage of coal, for inferred resources the results are $945,468.74 \mathrm{~m}^{3}$, indicated that the results are $700,020.23 \mathrm{~m}^{3}$, while for the measured resource the result is $349,335.77 \mathrm{~m}^{3}$, then multiplied by the density of coal that is 1.3 ton $/ \mathrm{m}^{3}$. The estimated inferred resource with a radius of $750 \mathrm{~m}$ obtained a tonnage of $1,229,109.36$ tons, an indicated resource with a radius of $500 \mathrm{~m}$ obtained a tonnage of $910,026.30$ tons. While the measured resource with a radius of $250 \mathrm{~m}$ obtained tonnage of $454,136.50$ tons.
\end{abstract}

Keywords: estimation; resources, coal; circular 891 USGS method 


\section{Pendahuluan}

Indonesia merupakan salah satu dari sepuluh negara penghasil batubara terbesar di seluruh dunia, memiliki cadangan sumberdaya batubara yang sangat melimpah, beberapa di antaranya yang terbesar terdapat di Pulau Sumatera dan Pulau Kalimantan (Balfas, 2015). Di Pulau Kalimantan hampir di setiap provinsi memiliki sumberdaya batubara. Salah satu di antara adalah Provinsi Kalimantan Timur.

Batubara merupakan suatu campuran padat yang heterogen dan terdapat di alam dalam tingkatan yang berbeda mulai dari lignit, subbitumit dan antrasit (Sukandarrumidi, 1995). Sumberdaya batubara (Coal Resources) adalah bagian dari endapan batubara yang diharapkan dapat dimanfaatkan. Sesuai Undang-Undang Dasar 1945 Pasal 33 ayat (3) menegaskan bahwa bumi, air, dan kekayaan alam yang terkandung di dalamnya dikuasai oleh negara dan dipergunakan untuk sebesarbesar kemakmuran rakyat. Mengingat mineral dan batubara sebagai kekayaan alam yang terkandung di dalam bumi merupakan sumberdaya alam yang tak terbarukan, pengelolaannya perlu dilakukan seoptimal mungkin, efisien, transparan, berkelanjutan dan berwawasan lingkungan, serta berkeadilan agar memperoleh manfaat sebesar-besar bagi kemakmuran rakyat secara berkelanjutan (Balfas, 2015).

Perhitungan sumberdaya yang akurat membantu para perancang tambang dapat membuat rencana penambangan yang optimal, baik dari segi produksi, segi waktu dan segi efisiensi biaya, bermuara pada pengambilan keputusan dalam teknis eksploitasi cadangan yang bernilai ekonomis (Jeremic, 1985). Prinsip perhitungan sumberdaya adalah berdasarkan pendekatan dari kondisi yang sebenarnya yang dihasilkan dari kegiatan eksplorasi (Horne et al., 1978).
Oleh karena itu, berdasarkan penjelasan di atas maka perlu dan penting estimasi sumberdaya batubara untuk dilakukan agar setiap kegiatan eksplorasi mulai dari awal hingga ke tahapan selanjutnya berjalan sesuai dengan standar yang ditetapkan pemerintah yang bersifat transparan karena batubara merupakan kekayaan negara yang dipergunakan untuk kemakmuran rakyat.

Studi ini dititikberatkan pada singkapan yang berada pada daerah penelitian yang memiliki kemenerusan yang sama dan diasumsikan satu seam yang sama berdasarkan kedudukan, roof dan floor, dan kenampakan secara fisik. Penelitian ini dilakukan di Daerah Tanah Merah, Kecamatan Samarinda Utara, Kota Samarinda, Provinsi Kalimantan Timur. Penelitian ini dilakukan karena sumberdaya yang dianggap prospek pada daerah penelitian.

\section{Metode Penelitian}

Penelitian berlokasi di daerah Tanah Merah, Kota Samarinda. Pada proses melakukan estimasi sumberdaya batubara metode yang digunakan adalah dengan membuat circular dari titik informasi berupa data singkapan dengan jarak antar titik informasi mengikuti kompleksitas geologi berdasarkan acuan SNI 5015:2011 (BSN, 2011). Metodologi dalam penelitian yang digunakan dalam penelitian ini meliputi:

1. Tahap Pralapangan; tahap pralapangan ini terdiri dari studi literatur, perumusan masalah, dan pengamatan lapangan.

2. Tahap Lapangan; pada tahap ini dilakukan pengumpulan data yang nantinya akan digunakan untuk mengetahui kondisi geologi dan melakukan estimasi sumberdaya batubara serta pola seberannya dengan data yang digunakan berupa data primer dan data sekunder.

3. Tahap Pasca lapangan; pada tahap pasca lapangan ini dilakukan pengolahan data yang telah didapatkan melalui tahap 
sebelumnya yaitu: pemetaan geologi, permodelan endapan batubara, korelasi, membuat pola sebaran batubara, dan estimasi sumberdaya batubara, hingga sampai ke hasil penelitian dan kesimpulan. Rumus untuk menghitung sumberdaya batubara menggunakan rumus Circular 891 USGS adalah sebagai berikut (GSC, 1983):

$$
\mathrm{T}=(\mathrm{L} / \cos \alpha) \times \mathrm{t} \times \mathrm{D}
$$

Keterangan:

$\mathrm{T}=$ tonase Batubara (ton)

$\mathrm{t}=$ tebal batubara $(\mathrm{m})$

$\mathrm{D}=$ berat batubara per volume

$\mathrm{L}=$ luas area batubara $\left(\mathrm{m}^{2}\right)$

$\mathrm{A}=\operatorname{dip}$ lapisan batubara $\left(^{\circ}\right)$

\section{Hasil dan Pembahasan}

\section{Geologi Daerah Penelitian}

Penentuan satuan batuan pada daerah penelitian didasarkan pada kesatuan ciri litologi dominan yang ada didaerah penelitian. Istilah satuan batuan digunakan berdasarkan ciri litologi serta posisi stratigrafi antar satuan batuan tersebut. Berdasarkan dari hasil pengamatan di lapangan terhadap litologi yang ada, satuan batuan pada daerah penelitian dibagi menjadi 3 (tiga) satuan batuan. Penamaan satuan batuan mengikuti tata nama litostratigrafi tidak resmi menurut Sandi Stratigrafi Indonesia dengan urutan muda sampai tua, sebagai berikut (Zaenal, 2019):

1. Endapan Aluvial

2. Satuan Batulempung Tanah Merah

3. Satuan Batupasir Tanah Merah

Secara umum pada daerah penelitian (Gambar 1) terdiri atas satuan batupasir tanah merah memiliki luasan $69 \%$ dan merupakan satuan yang paling tua, lalu diatasnya terendapkan secara selaras satuan batulempung tanah merah yang memiliki luasan $16 \%$, dan yang terakhir endapan alluvium.

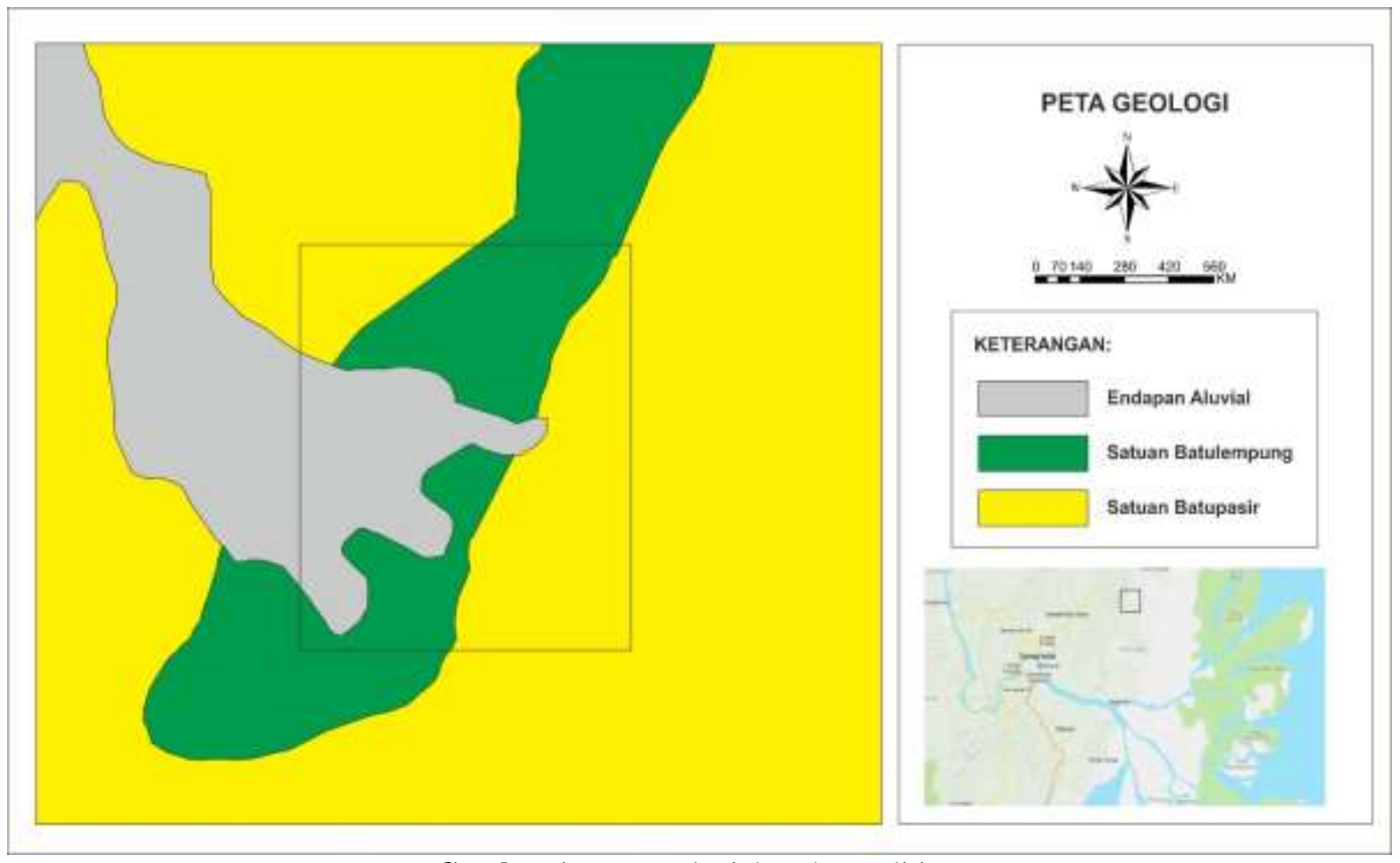

Gambar 1. Peta geologi daerah penelitian.

\section{Topografi}

Perbedaan relief pada bentang alam di daerah penelitian (Gambar 2) disebabkan oleh adanya perbedaan tingkat ketahanan batuan (resistensi) terhadap proses erosi yang terjadi di permukaan. Morfologi tinggian yang memiliki relief sedang 
hingga kasar dengan pola kontur yang sedang hingga rapat mencerminkan ekspresi dari litologi yang cukup resisten yaitu litologi yang berupa batupasir, sedangkan untuk morfologi dataran dan lembah yang memiliki relief halus hingga sedang dengan pola kontur yang jarang mencerminkan ekspresi dari litologi yang relatif kurang resisten, yaitu litologi yang berupa batulempung.

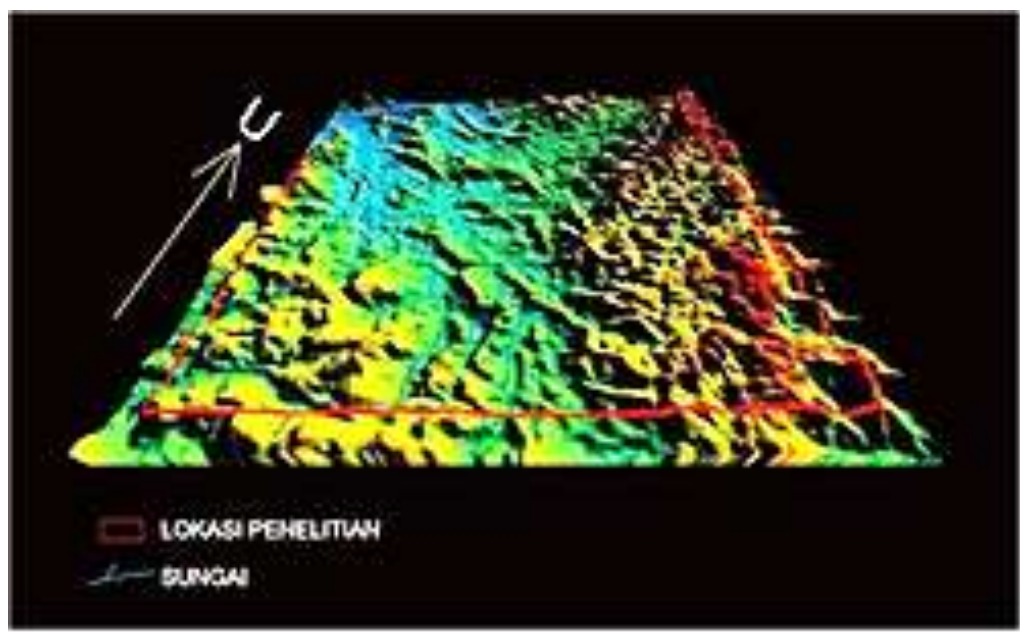

Gambar 2. Digital Elevation Model daerah penelitian

\section{Singkapan Batubara Daerah Penelitian}

Pada daerah penelitian, berdasarkan dari hasil pengamatan lapangan terdapat 3 titik singkapan batubara yang difokuskan yaitu pada Lokasi pengamatan 39, Lokasi pengamatan 40, dan Lokasi pengamatan 41 yang diasumsikan merupakan satu lapisan (seam) batubara yang sama berdasarkan kondisi roof dan floor, kedudukan lapisan batubara, dan kenampakan sifat fisik beserta nilai kalori batubara/ kualitas (Wood et al., 1983).

1. Lokasi Pengamatan 39, lokasi berada pada daerah Tanah Merah (dekat kuburan), Kondisi singkapan bekas kerukan alat berat dan sedikit lapuk. Kedudukan lapisan $\mathrm{N} 204^{\circ} \mathrm{E} / 72^{\circ}$. Pengukuran kedudukan dilakukan pada top batubara. Tebal $6,10 \mathrm{~m}$, warna: hitam, gores: coklat kehitaman, blocky, rekahan (cleat) terbentuk tegak lurus terhadap bidang perlapisan, kusam (dull), pengotor: resin, komposisi: karbon, roof/ top: batulempung, floor/ bottom: karbonan, singkapan berada pada dinding lereng, bentuk lapisan batubara melembar.

2. Lokasi Pengamatan 40, lokasi berada pada daerah Tanah Merah (dekat kuburan), Kondisi singkapan bekas kerukan alat berat dan sedikit lapuk, kedudukan lapisan $\mathrm{N} 205^{\circ} \mathrm{E} / 70^{\circ}$, pengukuran kedudukan dilakukan pada top batubara, tebal: $5,87 \mathrm{~m}$, warna: hitam, gores: coklat kehitaman, blocky, rekahan (cleat) terbentuk tegak lurus terhadap bidang perlapisan, kusam (dull), roof/ top: batulempung, floor/ bottom: batulempung, singkapan berada pada dinding lereng yang pada bagian top batubara mengalami longsor.

3. Lokasi Pengamatan 41, lokasi berada pada daerah Tanah Merah, kondisi singkapan bekas penambangan dan sedikit lapuk, kedudukan lapisan $\mathrm{N} 207^{\circ} \mathrm{E} / 74^{\circ}$, pengukuran kedudukan dilakukan pada top batubara, tebal: 3,20 m, warna: hitam, gores: coklat kehitaman, blocky, rekahan (cleat) terbentuk tegak lurus terhadap bidang perlapisan, kusam (dull), roof/ top: batulempung, floor/ bottom: karbonan, singkapan ini berada pada lereng bekas penambangan.

\section{Karakteristik Lapisan Batubara Daerah Penelitian}


1. Ketebalan; ketebalan lapisan batubara merupakan unsur penting yang langsung berhubungan dengan perhitungan atau estimasi sumberdaya. Lapisan batubara di daerah penelitian mempunyai ketebalan yang bervariasi yakni berkisar antara 0,30 meter hingga 6,76 meter.

2. Kemiringan Lapisan Batubara; hasil pengamatan singkapan di lapangan (data singkapan) lapisan batubara memiliki kemiringan yang bervariasi yakni antara $27^{\circ}-80^{\circ}$ dan termasuk

kedalam kategori landai sampai dengan miring curam.

3. Pola Sebaran Batubara Daerah Penelitian; hal ini terlihat dari kemiringan lapisan dan variasi ketebalan yang relatif beragam. Rekonstruksi data lapangan diketahui bahwa lapisan batubara mengikuti pola struktur yang ada berupa struktur lipatan, pola jurus relatif berarah timurlaut - baratdaya dengan kisaran kemiringan lapisan 70 (Gambar 3), dan memiliki arah kemiringan yang sama.

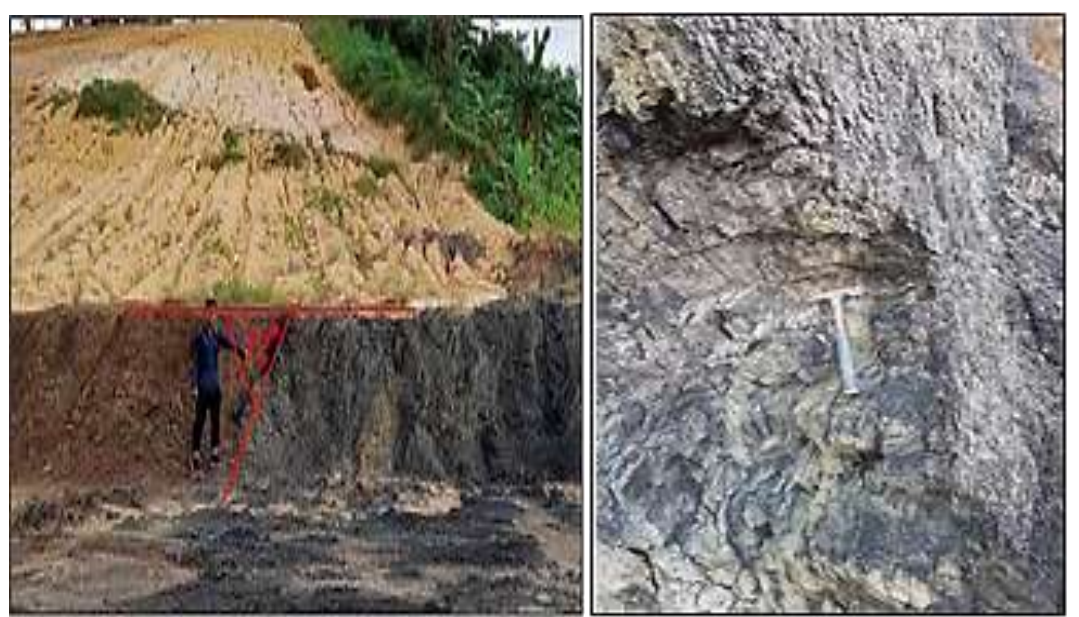

Gambar 3. Kenampakan batubara daerah penelitian (Lokasi Pengamatan 41)

4. Kemenerusan Lapisan Batubara; kemenerusan lapisan batubara di daerah penelitian masih dapat diikuti hingga beberapa ratus meter. Kejadian yang mempengaruhi kemenerusan lapisan batubara yang ada di lokasi penelitian ini juga dipengaruhi oleh proses-proses geologi, Faktor - faktor pengendali kemenerusan lapisan batubara adalah sedimentasi dan tektonik, pembahasan mengenai faktor pengendali kemenerusan lapisan batubara adalah sebagai berikut:

- Sedimentasi; kemenerusan lapisan batubara relatif normal dengan pola sebaran mengikuti pola kemenerusan batuan di sekitarnya yaitu ke arah timurlaut - baratdaya. Proses pengendapan lapisan batubara yang cenderung menipis ke arah timurlaut daerah penelitian.

- Tektonik; proses struktur geologi juga berkembang yang dibuktikan dengan terdapatnya lipatan dan patahan berdasarkan rekonstruksi struktur geologi yang telah dilakukan, sehingga mempengaruhi pola kemenerusan lapisan batubara yang membelok dan bergeser pada bagian selatan daerah penelitian, dapat dilihat dari pola sebaran batubara yang relatif ke arah timurlautbaratdaya.

5. Bentuk; berdasarkan pengamatan lapangan, singkapan batubara di daerah penelitian diinterpretasikan bahwa lapisan batubara memiliki bentuk melembar dan meluas. Hal ini dikarenakan tidak terdapatnya data 
penunjang geologi bawah permukaan untuk mengetahui apakah lapisan batubara memiliki bentuk lain seperti horseback, fault ataupun fold.

6. Rekahan (Cleat); rekahan lapisan batubara memiliki kedudukan $\mathrm{N} 345^{\circ} \mathrm{E} / 36^{\circ}, \mathrm{N} 0^{\circ} \mathrm{E} / 70^{\circ}, \mathrm{N} 10^{\circ} \mathrm{E} / 62^{\circ}$, $\mathrm{N} 215^{\circ} \mathrm{E} / 75^{\circ}, \quad \mathrm{N} 290^{\circ} \mathrm{E} / 55^{\circ}$, $\mathrm{N} 340^{\circ} \mathrm{E} / 75^{\circ}, \quad \mathrm{N} 305^{\circ} \mathrm{E} / 50^{\circ}$, $\mathrm{N} 245^{\circ} \mathrm{E} / 57^{\circ}$ dengan lebar bukaan antara $1-6 \mathrm{~mm}$ dan rekahan ini terbentuk tegak lurus dengan bidang perlapisan batubara.

7. Pelapukan; singkapan batubara di daerah penelitian termasuk ke dalam tingkat pelapukan lemah dikarenakan banyak lapisan batubara yang baru terbuka oleh aktivitas penambangan atau pun pembukaan lahan. Sehingga secara umum lapisan batubara dalam kondisi segar.

8. Kondisi Roof dan Floor; kontak batubara antara roof dan floor di daerah penelitian menunjukkan kontak yang berangsur yang mengindikasikan bahwa proses pengendapan berlangsung secara perlahan, tetapi di beberapa tempat menunjukkan proses yang berlangsung secara tiba-tiba pada bagian roof yang terendapkan litologi batupasir.

9. Keteraturan Lapisan Batubara; keteraturan lapisan batubara ditentukan oleh pola kedudukan lapisan batubara (jurus dan kemiringan) di daerah penelitian dengan kedudukan yakni $\mathrm{N} 204^{\circ} \mathrm{E} / 72^{\circ}, \quad \mathrm{N} 205^{\circ} \mathrm{E} / 70^{\circ}$ $\mathrm{N} 207^{\circ} \mathrm{E} / 74^{\circ}$. Pola lapisan batubara di permukaan menunjukkan pola yang teratur dengan garis menerus yang lurus dan meliuk/ melengkung pada elevasi yang sama.

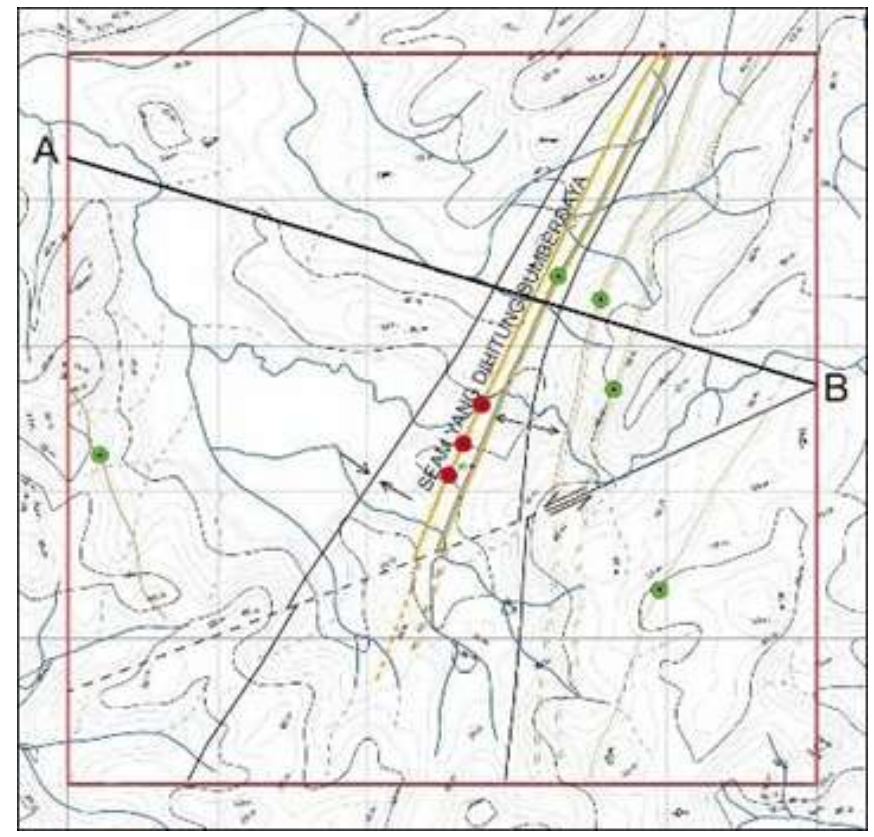

Gambar 4. Sebaran lapisan batubara seam 1 daerah penelitian.

10. Korelasi; metode korelasi yang dilakukan yaitu lithokorelasi yang menghubungkan unit yang sama litologi dan posisi stratigrafinya. Berdasarkan kolom stratigrafi daerah penelitian, korelasi dilakukan pada seam 1 yang diwakili oleh 3 singkapan yaitu LP 39, LP 40, dan LP 41 (Gambar 4). Roof dan floor batubara pada tiap singkapan yang dikorelasikan memiliki karakteristik yang sama, yaitu berupa batulempung dan karbonan. Lapisan batubara juga mengalami perubahan 
dimensi yaitu menipis ke kanan (timurlaut daerah penelitian) dan menebal pada bagian tengah (atau ke arah relatif baratdaya daerah penelitian) dari lapisan batubara. Total panjang singkapan yang dikorelasikan yaitu $423 \mathrm{~m}$ dengan skala horizontal 1:1500 dan skala vertikal 1:100.

\section{Permodelan Endapan Batubara}

Permodelan batubara dilakukan untuk mengetahui gambaran secara 2D atau 3D dari lapisan batubara yang telah diketahui keberadaannya. Pemodelan endapan batubara dilakukan berdasarkan dari data singkapan yang didapatkan di lapangan kemudian dilakukan permodelan dengan bantuan software geologi.

Selanjutnya kontur struktur ini dibuat berdasarkan data singkapan yang diolah dengan menggunakan bantuan software geologi kemudian diekstrapolasi dengan jarak 400 meter. Blok model kemudian dibuat yang merupakan gambaran proyeksi dari setiap sumberdaya dengan kemiringan lapisan batubara yang ditentukan berdasarkan karakteristik/ kompleksitas geologi di daerah penelitian yakni moderat, yang menjadi radius koreksi dalam perhitungan sumberdaya. Hasilnya dapat dilihat pada Gambar 5.
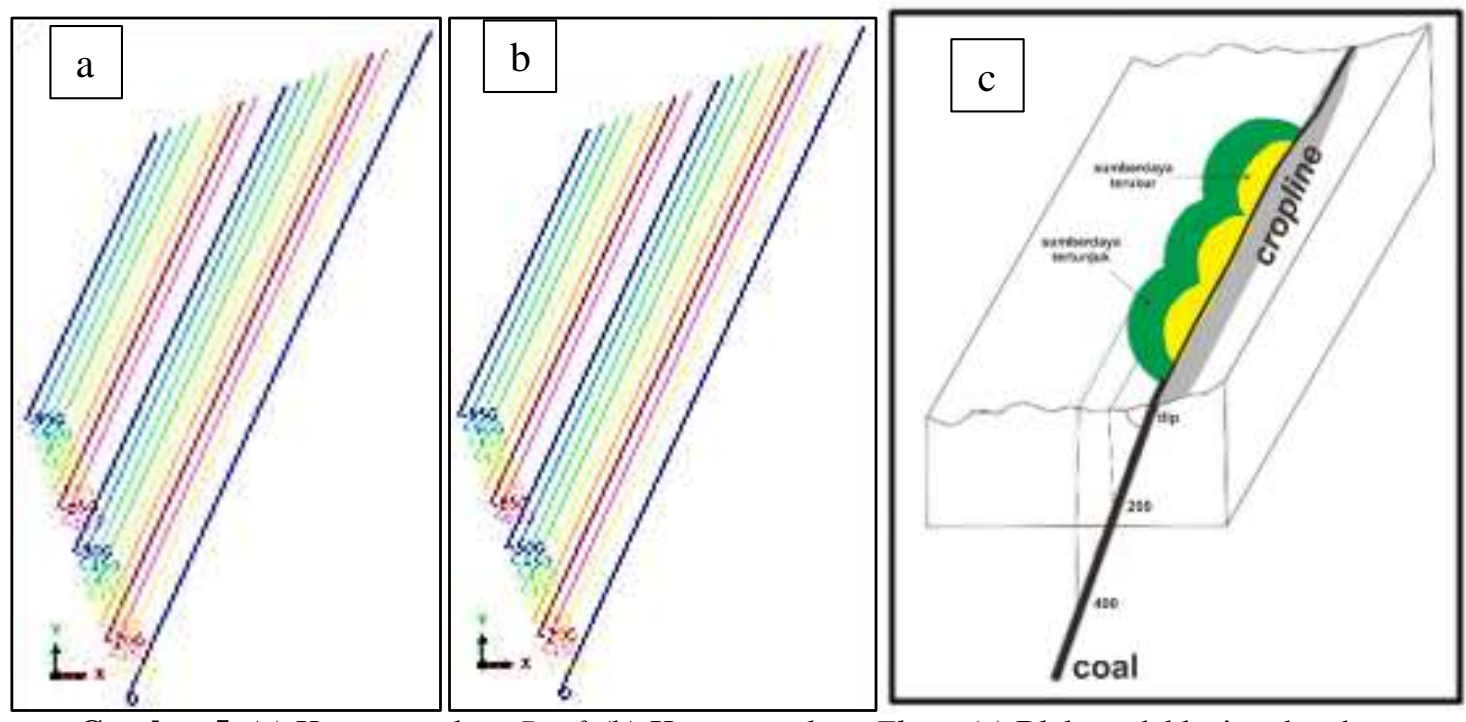

Gambar 5. (a) Kontur struktur Roof. (b) Kontur struktur Floor. (c) Blok model lapisan batubara.

\section{Estimasi Sumberdaya Batubara Daerah Penelitian}

Estimasi sumberdaya batubara di daerah penelitian menggunakan metode estimasi Circular USGS yang dipengaruhi oleh kemiringan perlapisan batubara yaitu $70^{\circ}$. Hasil perhitungan sumberdaya batubara diperoleh sebagai berikut (Gambar 6):

1. Sumberdaya Tereka

Luas area (L) batubara diperoleh dari hasil perhitungan menggunakan ArcGis 10.2 dengan membuat radius daerah pengaruh $750 \mathrm{~m}$ dari titik informasi, maka diperoleh luas area (L') sebesar $547.399,14 \mathrm{~m}^{2}$. Luas area terkoreksi (L) batubara diperoleh dari hasil perkalian L' dengan nilai cosinus kemiringan perlapisan batubara yaitu $70^{\circ}$. Maka diperoleh hasil 187.221,53 $\mathrm{m}^{2}$.

Volume batubara pada daerah penelitian dihitung dengan menggunakan variabel luas area terkoreksi dikalikan dengan tebal rata rata tiap singkapan batubara (tebal rata-rata $=5,05 \mathrm{~m}$ ), maka diperoleh total volume batubara tereka yaitu $945.468,74 \mathrm{~m}^{3}$.

Tonase sumberdaya tereka batubara diperoleh dari hasil perhitungan volume batubara dikalikan dengan densitas batubara $\left(1,3 \mathrm{ton} / \mathrm{m}^{3}\right)$, maka diperoleh 
tonase sumberdaya tereka batubara yaitu 1.229.109,36 ton.

2. Sumberdaya Tertunjuk

Luas area (L) batubara diperoleh dari hasil perhitungan menggunakan software geologi dengan membuat radius daerah pengaruh $500 \mathrm{~m}$ dari titik informasi, maka diperoleh luas area (L') sebesar 405.291,53 $\mathrm{m}^{2}$. Luas area terkoreksi (L) batubara diperoleh dari hasil perkalian L' dengan nilai cosinus kemiringan perlapisan batubara yaitu $70^{\circ}$. Maka diperoleh hasil 138.617,87 $\mathrm{m}^{2}$.

Volume batubara pada daerah penelitian dihitung dengan menggunakan variabel luas area terkoreksi dikalikan dengan tebal rata rata tiap singkapan batubara (tebal rata-rata $=5,05 \mathrm{~m}$ ), maka diperoleh total volume batubara tertunjuk yaitu $700.020,23 \mathrm{~m}^{3}$. Tonase sumberdaya tereka batubara diperoleh dari hasil perhitungan volume batubara dikalikan dengan densitas batubara $(1,3$ ton $\left./ \mathrm{m}^{3}\right)$, maka diperoleh Tonase sumberdaya tereka batubara yaitu 910.026,30 ton.

3. Sumberdaya Terukur

Luas area (L') batubara diperoleh dari hasil perhitungan menggunakan software geologi dengan membuat radius daerah pengaruh $250 \mathrm{~m}$ dari titik informasi, maka diperoleh luas area (L') sebesar 202.225,34 $\mathrm{m}^{2}$. Luas area terkoreksi (L) batubara diperoleh dari hasil perkalian L' dengan nilai cosinus kemiringan perlapisan batubara yaitu $70^{\circ}$. Maka diperoleh hasil 69.175,40 $\mathrm{m}^{2}$. Volume batubara pada daerah penelitian dihitung dengan menggunakan variabel luas area terkoreksi dikalikan dengan tebal rata rata tiap singkapan batubara (tebal rata-rata $=5,05 \mathrm{~m}$ ), maka diperoleh total volume batubara terukur yaitu 349.335,77 $\mathrm{m}^{3}$. Tonase sumberdaya tereka batubara diperoleh dari hasil perhitungan volume batubara dikalikan dengan densitas batubara $(1,3$ ton $/ \mathrm{m}^{3}$ ), maka diperoleh tonase sumberdaya tereka batubara yaitu 454.136,50 ton.

Terjadi perbedaan hasil perhitungan sumberdaya batubara, mulai dari sumberdaya tereka, tertunjuk, dan terukur disebabkan jarak perhitungan sumberdaya batubara. Jarak ini dianggap sebagai kemenerusan lapisan batubara di bawah permukaan. Semakin jauh jaraknya, semakin besar sumberdaya yang dihasilkan, namun bisa kurang akurat karena kompleksitas kondisi geologi bawah permukaan yang tidak terekam oleh data lapangan. Oleh karena itu, jarak yang semakin kecil memberikan hasil lebih akurat disebabkan jarak yang diambil masih dalam batas kemenerusan batubara tanpa atau dengan sedikit kompleksitas geologi bawah permukaan.

\section{Kesimpulan}

Pola sebaran lapisan batubara di daerah Tanah Merah dikontrol oleh struktur lipatan dan sesar yang intensif. Lipatan yang terdapat di daerah penelitian berupa sinklin dan antiklin. Persebaran batubara memiliki pola yang teratur dengan orientasi relatif berarah timurlaut - baratdaya dengan mengikuti litologi batuan di sekitarnya.

Kontur struktur batubara dibuat berdasarkan data singkapan yang menunjukkan hasil berupa garis - garis yang memiliki pola kemenerusan yang sama dan menggambarkan kedalaman lapisan batubara dari permukaan.

Besar sumberdaya tereka yaitu sebesar 1.229.109,36 ton, besar sumberdaya tertunjuk yaitu sebesar 910.026,30 ton, besar sumberdaya terukur yaitu sebesar 454.136,50 ton.

\section{Daftar Pustaka}

BSN (Badan Standarisasi Nasional). 2011. Klasifikasi Sumberdaya dan 
Cadangan Batubara. Rancangan Standarisasi Nasional Indonesia.

Balfas, M.D. 2015. Geologi untuk Pertambangan Umum. Yogyakarta: Graha Ilmu.

GSC (Geology Survey Circular 891). 1983. Coal Resource Classification System of U.S. Geological Survey. USGS. https://pubs.usgs.gov/circ/1983/089 1/report.pdf

Horne, J.C., Ferm, J.C., Caruccio, F.T. and Baganz, B.P. 1978. Depositional Models in Coal Exploration and Mine Planning in Appalachian Region. AAPG Bulletin. 62(12), pp.2379 -2411 . https://doi.org/10.1306/C1EA551216C9-11D7-8645000102C1865D.
Jeremic, M.L. 1985. Strata Mechanics in Coal Mining. London: CRC Press. https://doi.org/10.1201/978100307 $\underline{9170}$

Sukandarrumidi. 1995. Batubara dan Gambut. Yogyakarta: Gajah Mada University Press.

Wood, G.H., Kehn, T,M., Carter, M.D. and Culbertson, W.C. 1983. Coal Resource Classification System of the U.S. Geological Survey. USGS. https://pubs.usgs.gov/circ/c891/

Zaenal, M.M. 2019. Geologi Daerah Tanah Merah dan Sekitarnya Kecamatan Samarinda Utara, Samarinda, Kalimantan Timur. (unpublished) 